\title{
Is Billiards Considered A Sport?
}

\author{
Dr. Mohammed Abou Elmagd"
}

Sports Manager, Student Affairs, Physical Activity Department, Ras Al Khaimah Medical and Health Sciences University, RAK, 11172, United Arab Emirates

DOI: 10.36348/JASPE.2019.v02i07.006 | Received: 21.09.2019| Accepted: 28.09.2019| Published: 30.09 .2019

*Corresponding author: Dr. Mohammed Abou Elmagd

Abstract

Understanding the differences between games and sports can be done when we can identify the two terms as two different words. A sport is a physical activity carried out under fixed set of rules, with competition or self-enjoyment or a combination of both. A game is a recreational activity involving one or more players, defined by a goal that the players try to reach, and some set of rules to play it. Most of the people is confused between Sport and game because the word game has several meanings. Actually we can play a game of sports, but we can't sport a game. Olympics they are called the OLYMPIC GAMES and all the competitions are in specific Sports. Cue sports are a wide variety of games of skill generally played with a cue stick which is used to strike billiard balls, moving them around a cloth-covered billiards table surrounded by rubber cushions. Billiards is a sport, and you can play different games within the sport: eight- ball, nineball, three ball, one pocket and bank pool. Pocket Billiards has been declared a Sport by the Olympic Committee. Billiards category including pool, snooker and carom was presented in the 2005 World Games, held in Duisburg, Germany, and the 2006 Asian Games as a cue sports category. Thus, definitely billiards should be announced as a sport.

Keywords: sport, game, cue sports, billiards, physical activity.

Copyright @ 2019: This is an open-access article distributed under the terms of the Creative Commons Attribution license which permits unrestricted use, distribution, and reproduction in any medium for non-commercial use (NonCommercial, or CC-BY-NC) provided the original author and source are credited.

\section{INTRODUCTION}

People often take game and sport as to be the same one. However, game and sport are different. Sport includes all forms of competitive physical activity or games which [1], through casual or organized participation, aim to use, maintain or improve physical ability and skills while providing enjoyment to participants, and in some cases, entertainment for audiences [2]. Sport is generally recognized as system of activities which are based in physical flexibility or physical agility, with the largest main competitions such as the Olympic Games admitting only sports meeting this definition [3]. A physical activity, Sport is carried out under a fixed set of rules. On the other hand a game is a structured form of play, usually assumed for enjoyment and sometimes used as an educational tool [4]. Sport is related to entertaining purpose, either for self-enjoyment or competition or for both. A game is also for entertaining activities and it involves one or more players played on the basis of a set of rules, a game is also defined as a goal that the players try to achieve. Sport is an activity or activities where the material skills of the sportsperson are observed. In a sport, it is the sportsperson or the individual who determines the outcome. Well, an individual's talent does not determine a game. It is the entire performance of the players that decides the winner in a game [5].

A person participating in a sport is called as athlete or a sports person. A person who participates in a game is known as player. When a game relies on strategy, sport is based on individual performances and luck. In a sport, the athlete can take independent decisions, but a player cannot take such independent decisions in a game. A decision is taken at a game collectively among two or more players. Another difference between them is that the sport is based on physical energy and the game is based on mental strength. Sport is played with a view of competition in mind while game is played with a friendly attitude. One can come across more efficiency in sport than the game. In a sport, the athlete or sports person is expected to show good sportsmanship and also have high standards of conduct like respecting the challengers and the officials. But in a game, an individual may not deliver such personality. In game, the performance of the whole team is taken into account. Sport is organized and competitive. It also requires commitment and fair play. An athlete or a sports person always gain popularity and maintains a name for his skills. But in a game, it is not 
the individual who gains popularity but it is the entire team that gets a place.

Cue sports, also known as billiard sports[6,7] are a wide variety of games of skill generally played with a cue stick which is used to strike billiard balls, moving them around a cloth-covered billiards table bounded by rubber cushions. Historically, the umbrella term was billiards. While that familiar name is still employed by some as a generic label for all such games. For example, in British and Australian English, "billiards" usually refers exclusively to the game of English billiards, while in American and Canadian English it is sometimes used to refer to a particular game or class of games, or to all cue games in general, depending upon dialect and context.

\section{There are three major subdivisions of games within cue sports}

- Carom billiards, referring to games played on tables without pockets, typically 10 feet in length, including balk line and straight rail, cushion caroms, three-cushion billiards, artistic billiards and four-ball.

- Pool, covering numerous pocket billiards games generally played on six-pocket tables of 7-, 8-, or 9-foot length, including among others eight-ball (the world's most widely played cue sport), nineball (the dominant professional game), ten-ball, straight pool (the formerly dominant pro game), one-pocket, and bank pool.

- Snooker and English billiards, games played on a billiards table with six pockets called a snooker table (which has dimensions just under $12 \mathrm{ft}$ by $6 \mathrm{ft}$ ), that are classified totally separately from pool based on a separate historical development, as well as a separate culture and terminology that characterize their play.

\section{Game history}

All cue sports are generally considered to have developed into indoor games from outdoor stick-andball [8]. The word "billiard" may have developed from the French word billart or billette, meaning "stick", in reference to the mace, an implement similar to a golf club, which was the sign to the modern cue; the term's origin may have also been from French bille, meaning "ball[9] ". The modern term "cue sports" can be used to involve the ancestral mace games, and even the modern cue less variants, such as finger billiards, for historical reasons. "Cue" itself came from queue, the French word for a tail. This refers to the early practice of using the tail of the mace to strike the ball when it lay against a rail cushion. A recognizable form of billiards was played outdoors in the 1340s, and was reminiscent of croquet. King Louis XI of France (1461-1483) had the first known indoor billiard table ${ }^{[10]}$. Louis XIV further developed and promoted the game, and it quickly spread among the French nobility. While the game had long been played on the ground, this version appears to have died out in the 17th century, in favor of croquet, golf and bowling games, while table billiards had grown in popularity as an indoor activity. Mary, Queen of Scots, claimed that her "table de billiard" had been taken away by those who eventually became her executioners (and who covered her body with the table's cloth). In 1588, the Duke of Norfolk, owned a "billiard board covered with a green cloth... three billiard sticks and 11 balls ". Billiards grew to the extent that by 1727 , it was being played in almost every Paris café, and was played by the French nobility until the Revolution. In England, the game was developing into a very popular activity for members of the gentry [11].

The main billiard game in Britain from about 1770 until the 1920's was English Billiards, played with three balls and six pockets on a large rectangular table. The British billiard tradition is carried on today primarily through the game of snooker, a complex and colorful game combining offensive and defensive aspects and played on the same equipment as English Billiards but with 22 balls instead of three. The British appetite for snooker is approached only by the American passion for baseball; it is possible to see a snooker competition every day in Britain. The dominant American billiard game until the 1870's was American Four-Ball Billiards, usually played on a large (11 or 12foot), four-pocket table with four balls - two white and two red. It was a direct extension English Billiards. Points were scored by pocketing balls, scratching the cue ball, or by making caroms on two or three balls. A "carom" is the act of hitting two object balls with the cue ball in one stroke. With many balls, there were many different ways of scoring and it was possible to make up to 13 pints on a single shot. American FourBall produced two offspring, both of which surpassed it in popularity by the 1870 's. One, simple caroms played with three balls on a pocket less table, is something known as "Straight rail", the forerunner of all carom games. The other popular game was American FifteenBall Pool, the predecessor of modern pocket billiards.

Eight-Ball was invented shortly after 1900; Straight Pool followed in 1910. Nine-Ball seems to have developed around 1920. While the term "billiards" refers to all games played on a billiard table, with or without pockets, some people take billiards to mean carom games only and use pool for pocket games. Through the 1930's, both pool and billiards, particularly three-cushion billiards, shared the spotlight. From 1878 until 1956, pool and billiard championship tournaments were held almost annually, with one-on-one challenge matches filling the remaining months. At times, including during the Civil War, billiard results received wider coverage than war news. Players were so renowned that cigarette cards were issued featuring them. Pool went to war several times as a popular recreation for the troops. Professional players toured military posts giving exhibitions; some even worked in the defense Industry. But the game had more trouble 
emerging from World War II than it had getting into it. Returning soldiers were in a mood to buy houses and build careers, and the charm of an afternoon spent at the pool table was a thing of the past. Room after room closed quietly and by the end of the 1950's it looked as though the game might pass into oblivion.

In the 1920's, the billiards room was an environment in which men met and play. The rooms of today bear no similarity to those of the earlier times. Until very lately, billiards was completely controlled by men. The atmosphere of the poolroom was very forbidding and women had trouble being accepted there. However, women have been enthusiastic players since the game was brought up from the ground in the 15 th century. For over 200 hundred years, women of fashion have played the game. In the past, it was very difficult for a woman to develop billiard skills because male players, her family, and friends usually did not support her efforts and it was not easy to find experienced female instructors or coaches. As these situations have changed, and continue to change, we can expect women to equal men in ability and take the game to new levels [12].

In the United States pool and billiards had died out for a bit, but between 1878 and 1956 pool and billiards became very popular. Players in annual championships began to receive their own cigarette cards. This was mainly due to the fact that it was a popular pastime for troops to take their minds off from battle. However, by the end of World War II pool and billiards began to die down once again. It was not until 1961 when the film "The Hustler" came out that sparked a new interest in the game. Now the game is generally a well-known game and has many players of all different skill levels [13].

\section{Game types}

\section{Eight-ball}

In the United States, the most common game is eight-ball. The goal of eight-ball, which is played with a full rack of fifteen balls and the cue ball, is to claim a suit (commonly stripes or solids in the US, and reds or yellows in the UK), pocket all of them, then legally pocket the 8 ball, and without sinking the 8 ball early by accident. In the United Kingdom the game is commonly played in pubs, and it is competitively played in leagues on both sides of the Atlantic. The most important tournaments including the World Open are sponsored and approved by the International Pool Tour. Rules vary widely from place to place.

\section{Nine-ball}

Nine-ball uses only the 1 through 9 balls and cue ball. It is a rotation game: The player at the table must make legal contact with the lowest numbered ball on the table or a foul is called. The game is won by legally pocketing the nine ball. Nine-ball is the largest professional game, though as of 2006-2008 there have been some suggestions that this may change, in favor of ten-ball [14]. There are many local and regional tours and tournaments that are contested with nine-ball. The World Pool-Billiard Association (WPA) and its American associate, the Billiard Congress of America (BCA), publish the World Standardized Rules. The European professional circuit has instituted rules changes to make it more difficult to achieve a legal break shot [15].

\section{Ten-ball}

Is a modern pool game. It is a rotation game very similar to nine-ball, but more difficult, using 10 balls instead of nine, and with the 10 ball instead of the nine. Most of the same rules apply as in nine-ball. This means that in order to establish a legal hit, the cue ball must contact the lowest numbered ball first, and subsequently at least one ball must hit any rail, without the cue ball being pocketed. In 10-ball, shots have to be called, which means that the player must call a ball and the pocket in which to make the ball.

\section{Three-ball}

Using only three balls, generally played such that the player at turn continues shooting until all the balls are pocketed, and the player to do so in the fewest shots wins. The game can be played by two or more players. Distributes with some fouls common to both nine- and eight-ball.

\section{One-pocket}

One-pocket is a strategic game for two players. Each player is assigned one of the corner pockets on the table. This is the only pocket into which he can legally pocket balls. The first player to pocket the majority of the balls (8) in his pocket wins the game. The game requires far more defensive strategy than offensive strategy, much unlike eight-ball, nineball, or straight pool. Most times, talented players choose to position balls near their pocket instead of trying to actually pocket them. This allows them to control the game by forcing their opponent to be on defense instead of taking a low percentage shot that could result in a loss of game.

\section{Straight pool}

Also called 14.1 continuous or simply 14.1 , is a pocket billiards game. It was the common sport of championship competition until it was overtaken by faster-playing games. In straight pool, the shooter may attempt to shoot at any object ball on the table. The goal is to reach a set number of points determined by agreement before the game. One point is scored for each object ball pocketed where no foul is made. A typical game might require a player to score 100 points to win. In professional competition, straight pool is usually played to 125 points. Straight pool is a callpocket game, meaning the player must indicate the intended object ball and pocket on every shot. 


\section{Bank pool}

Bank pool has been gaining popularity in recent years. Bank pool can be played with a full rack, but is more typically played with nine balls. The balls are racked in nine-ball formation, but in no particular order. The object of the game is simple: to be the first player to bank five balls in any order (eight balls when played with a full rack). Penalties and fouls are similar to one pocket in that the player committing the foul must spot a ball for each foul. This must be done before the incoming player shoots [16].

\section{Main bodies of the game}

Pool is directed internationally by the World Pool-Billiard Association (WPA), which has multinational, regional associates comprising the All Africa Pool Association (AAPA), Asian Pocket Billiard Union (APBU, including the Middle East), Billiard Congress of America (BCA, Canada and the US), Confederation Pan America of Billiards (CPB, Latin America and Caribbean), European Pocket Billiard Federation (EPBF, including Russia and the Near East), and Oceania Pocket Billiard Association (OPBA, Australia, New Zealand, Pacific islands). ${ }^{[17]}$

\section{DISCUSSION}

There are two groups saying that Pool is a sport and the other side said no it's a game only, and did not reach to the level of sport. In this part $\mathrm{i}$ will clarify and proof that billiards consider as a sport for many reasons. First of all billiards placing enormous amounts of pressure on the chest, back, legs, and arms. You can ask any professional player about it he will clearly admit that sometimes he needs to do massage to his back or neck in order to be ready for the next shot. Pool required a much higher degree of physical exertion than many other activities called game like chess for example. Billiards should be considered a sport as it makes use of muscle energy, reflexes and burns a lot of energy in the process. Billiards also requires a lot of skill and concentration. So, in my opinion, anything we do that consists of skill and concentration should be considered a sport. Wherever you are in the world it's clear that both snooker and pool are famous a lot these days. They are up there with the likes of football, rugby, cricket, and tennis and should definitely be considered sports. It is a competition requiring physical ability in which the result is objectively determined, it is a challenge of skill with players going head to head to result in a winner. Pool requires accuracy skill and practice with full concentration. Try to invite anyone to play billiards for more than two hours straight without rest and see if he still strong on his legs, with fit arms and a clear focus, of course no so, Anything that requires a physical activity is a sport. When you are competing at a high level you take it seriously so, your will use all components of fitness, like power for when you strike a ball hard, accuracy to aim and pot the ball etc.
From the other side if we speak about the billiards organizations and federations we can judge that billiards is a sport. The World Confederation of Billiards Sports (WCBS) [18] is the international umbrella organization surrounding the major cue sports (billiards-type games), including carom billiards, pool games of several varieties, and snooker. The confederation is relatively new, having been founded in 1992[19]. Its current head office are in Sint-MartensLatem, Belgium. Jean-Claude Dupont is the current President since 2010 [20]. There are 148 affiliated national federations. It is affiliated with many international sports organizations such as the International Olympic Committee (IOC), General Association of International Sports Federations (GAISF), International World Games Association (IWGA) and Commonwealth Games Federation (CGF). Its statutes, practices and activities all conform to the Olympic Charter [21]. The World Pool-Billiard Association (WPA) represents pool in the World Confederation of Billiard Sports, which in turn represents all forms of cue sports (including carom billiards and snooker) in the International Olympic Committee.

\section{CONCLUSION}

Billiards is considered as a sport as it makes use of muscle energy, reflexes and burns a lot of energy in the process. Billiards also requires a lot of skill and concentration. In my opinion, anything we do that consists of skill, concentration and body movement should be considered a sport. Any games with structured international professional competition have been referred to as sports events, not simply "games. Billiards category including pool, snooker and carom was presented in the 2005 World Games, held in Duisburg, Germany, and the 2006 Asian Games as a cue sports category. Thus, definitely billiards should be considered as a sport.

\section{ACKNOWLEDGMENT}

The Author would like to express his gratitude to HE.Sheikh Mohammed bin Kayed Al Qasimi, Chairman of the Department of Economic Development - Ras Al Khaimah for his idea to start the research and his always personal support and contribution.

\section{REFERENCES}

1. Sport Accord.(2011). Archived from the original on 28 October 2011. Retrieved May 20, 2017

2. Council of Europe.(2017). "The Europien sport charter". Retrieved 5 March 2017.

3. List of summer and Winter Olympic Sports and Events(2017).". The Olympic Movement.

4. www.merriam-webster.com. Retrieved May 7, 2017.

5. http://www.differencebetween.net/miscellaneous/di fference-between-game-and-sport/ 
6. olympic.org - Official Website of the Olympic Movement. Lausanne, Switzerland: International Olympic Committee. 2009. pp. "Sports" section. Retrieved 2009-06-01.

7. World Confederation of Billiard Sports. 2005. pp. Homepage and very name of organization. Retrieved 2009-06-01.

8. Stein, V., \& Rubino, P. (1994). The billiard encyclopedia: an illustrated history of the sport. billiard encyclopedia.

9. Everton, C. (1986). The history of snooker and billiards. Partridge Press.

10. Everton, Clive. (1986). The History of Snooker and Billiards (rev. ver. of The Story of Billiards and Snooker, 1979 ed.). Haywards Heath, UK: Partridge Pr. pp. 8-11. ISBN 1-85225-013-5.

11. Gervais, C. E., Castric, V., Ressayre, A., \& Billiard, S. (2011). Origin and diversification dynamics of self-incompatibility haplotypes. Genetics, 188(3), 625-636.

12. http://www.thebilliardshop.com/history-of-pooland-billiards.

13. The Pool Shop. (2011). Retrieved December 2011.
14. Varner, Nick. (2008). "Killing Me Softly? The Outbreak of the Soft Break Threatens the Game of 9-ball". Billiards Digest. 30(3). Chicago,: Luby Publishing, 4-35.

15. Panozzo, Mike. (2008). "Long Live the Cup!". Billiards Digest. 30(3). Chicago, Luby Publishing. pp. 34-35.

16. http://www.rulesofsport.com/faq/is-pool-snookera-sport-or-a-game.html

17. Shamos, M. I. (1993). The Illustrated Encyclopedia of Billiards. Lyons \& Burford.

18. WCBS official website, accessed May 12, 2007. It is sometimes called the World Confederation of Billiards Sports; the logo on the site uses the singular form of the name, while copies of the organisation's founding documents on the site use the plural version.

19. Organization information at IOC homepage. Retrieved May 15, 2017

20. Members of the Board of Directors of WCBS. Retrieved May 11, 2017

21. Englishblackball.com Retrieved May 10, 2017. 